\title{
Efeito da alta pressão hidrostática na atividade de enzimas da polpa de açaí
}

\author{
High hydrostatic pressure effect on enzyme activity of açai pulp
}

\author{
Ellen Mayra da Silva MENEZES ${ }^{1 \star}$, Amauri ROSENTHAL ${ }^{2}$, Armando SABAA-SRUR ${ }^{3}$, \\ Lourdes CAMARGO², Verônica CALADO ${ }^{4}$, Ana SANTOS ${ }^{4}$
}

\section{Resumo}

O Brasil vem conquistando o mercado externo de sucos de frutos tropicais, com destaque para o açaí, muito procurado por ser conhecido como um alimento funcional, devido à concentração de antocianinas, fibras dietéticas e ácidos graxos monoinsaturados. Entretanto, o açaí é altamente perecível, necessitando de intervenções tecnológicas para prolongar sua vida de prateleira. Nesse caso, o uso da Alta Pressão Hidrostática (APH) pode ser uma alternativa aos processamentos tradicionais, por sua capacidade de ativar ou inativar enzimas. Peroxidases (POD) e polifenoloxidases (PFO) são as principais enzimas responsáveis por alterações indesejáveis das características originais de produtos vegetais e, com a sua inativação pela $\mathrm{APH}$, pode-se evitar o escurecimento enzimático e manter as suas propriedades sensoriais. Com o objetivo de avaliar o efeito da APH em POD e PFO de polpa de açaí, adotaram-se as variáveis de pressão, temperatura e tempo. As atividades enzimáticas expressas em percentuais revelaram a POD mais estável, atingindo percentuais próximos a 100\% (controle). As menores atividades foram a $90,74 \%$, e quando se aplicaram 300 e $500 \mathrm{MPa}$ a $25^{\circ} \mathrm{C}$ por 5 minutos, as atividades aumentaram (112,34 e 132,98\%, respectivamente). A atividade da $\mathrm{PFO}$ aumentou até $83,03 \%$ em relação ao controle, embora apresentasse inativação na maioria dos processos, evidenciando-se atividade a $35^{\circ} \mathrm{C} / 5$ minutos de 53,25 e 53,75\% a 300 e $500 \mathrm{MPa}$, respectivamente. Diante das condições experimentais, a APH mostrou-se eficaz na inativação parcial de oxidases na polpa de açaí.

Palavras-chave: Euterpe oleracea, Mart.; alta pressão hidrostática; peroxidase; polifenoloxidase.

\begin{abstract}
Brazil has been conquering tropical fruit juice international market, especially with açaí (native fruit with the highest penetration in the international), considered a functional food for its anthocyanin, dietetic fibe, and monounsaturated fat content. However, açaí is very perishable, so the use of technology is needed in order to ensure long shelf life. In this case, High Hydrostatic Pressure (HHP) use can be an alternative to traditional processing techniques for enzyme activation or inactivation. Peroxidases (POD) and Polyphenoloxidases (PPO) are the main enzymes responsible for undesirable changes in the original characteristics of vegetable products, but using HHP to inactivate them, it is possible to avoid enzymatic browning maintaining sensorial properties. Aiming to evaluate HHP effect on POD and PPO, present in the açaí pulp, the variables pressure, temperature, and time were adopted. Enzyme activities, expressed in percentages, indicate a more stable POD, achieving percentages close to $100 \%$ (control). The lowest activities were at $90.74 \%$, and when applied 300 and $500 \mathrm{MPa}, 25^{\circ} \mathrm{C}$ for 5 minutes treatments, the activities increased ( 112.34 and $132.98 \%$, respectively). PPO activity rose up to $83.03 \%$ in relation to the to control even though inactivation was present in most of the processes $\left(35^{\circ} \mathrm{C} / 5\right.$ minutes at 300 and $500 \mathrm{MPa}, 53.25$, and $53.75 \%$, respectively). Under the experimental conditions, HHP proved effective for the partial inactivation of açaí pulp oxidases.

Keywords: açai; high hydrostatic pressure; peroxidase; polyphenoloxidase.
\end{abstract}

\section{Introdução}

O Brasil, possuidor de uma fruticultura diversificada, é considerado o terceiro maior produtor de frutas frescas, com cerca de 38 milhões de toneladas anuais, atrás da China e Índia. Um dos líderes também em exportação de frutas, vem investindo no contínuo crescimento deste pólo com programas de erradicação ou de controle de doenças em frutos e buscando a modernização dos processos de produção (BEZERRA, 2004). Aliada a isso, a indústria de sucos de frutas apresenta-se em grande expansão, conquistando inclusive mercados externos de sucos de frutos tropicais em função de qualidade, valor nutritivo e sabores exóticos desses produtos (MAPA, 2004).

Dentre esses frutos, o açaí (Euterpe oleracea, Mart.), típico da Amazônia, teve uma produção no país de aproximadamente 740 mil toneladas de 1999 até 2004 (MONTEIRO, 2006). Ele é matéria-prima para produção de polpa ou suco, alimento altamente energético, por possuir significativo teor lipídico, e com grande apelo funcional em razão do conteúdo de antocia-

Recebido para publicação em 30/1/2007

Aceito para publicação em 17/7/2008 (002551)

${ }^{1}$ Instituto de Tecnologia - IT, Universidade Federal Rural do Rio de Janeiro - UFRRJ, BR 465, Km 07, CEP 23890-000, Seropédica - RJ, Brasil, E-mail: ellenmayra@hotmail.com

2 Embrapa Agroindústria de Alimentos, Av. das Américas, 29501, CEP 23020-470, Rio de Janeiro - RJ, Brasil, E-mail: arosent@ctaa.embrapa.br

${ }^{3}$ Centro de Ciências da Saúde - CCS, Departamento de Nutrição Básica e Experimental - DNBE, Instituto de Nutrição - IN, Universidade Federal do Rio de Janeiro - UFRJ, Av. Brigadeiro Trompowski, Bloco J, $2^{\circ}$ andar, sala 15, CEP 21949-900, Ilha da Cidade Universitária, Rio de Janeiro - RJ, Brasil, E-mail: sabaasrur@yahoo.com.br

${ }^{4}$ Centro de Tecnologia - CT, Escola de Química - EQ, Universidade Federal do Rio de Janeiro - UFRJ, Av. Athos da Silveira Ramos 149, Bloco A, 2ªndar, CEP 21941-909,

Rio de Janeiro - RJ, Brasil, E-mail: calado@eq.ufrj.br

${ }^{*}$ A quem a correspondência deve ser enviada 
ninas, fibras e outras substâncias nutracêuticas (ROGEZ, 2000; OLIVEIRA et al., 2002; SABAA-SRUR; TORRES; MENEZES, 2004; YUYAMA, 2004). Porém, esse produto é altamente perecível (ALEXANDRE; CUNHA; HUBINGER, 2004) devido às práticas pós-colheita a que o fruto é submetido, relacionadas com a colheita dos cachos, remoção dos frutos desses cachos, transporte e condições ambientais desfavoráveis, como altas temperaturas e alta umidade relativa (MENEZES, 2005). Além disso, no processo de obtenção da polpa, a manipulação favorece a proliferação de microrganismos e reações enzimáticas, principais responsáveis pela deterioração desse produto (ROGEZ, 2000; MENEZES, 2005; SOUSA et al., 2006).

Apesar da grande eficiência nas tecnologias tradicionais de conservação, tratamentos térmicos com emprego de altas temperaturas podem causar alterações indesejáveis nos produtos processados, por afetarem atributos nutricionais e sensoriais (CLEMENTE, 2002; DEL POZO INSFRAN et al., 2007). Por outro lado, há uma crescente demanda de consumidores por alimentos frescos, impulsionando o surgimento de pesquisas que visam novas tecnologias na produção de alimentos seguros, com o mínimo de perda nutricional e sensorial, mantendo-os mais próximos do seu valor in natura e com uma maior estabilidade na sua vida de prateleira (BUTZ et al., 2003; MONTEIRO, 2006). Tecnologias não convencionais, como a Alta Pressão Hidrostática (APH), estão sendo pesquisadas como processo alternativo ou complementar aos métodos tradicionais (BUTZ et al., 2002a; BUTZ et al., 2002b; SAN-MARTÍN; BARBOSA-CÁNOVAS; SWANSON, 2002; BUTZ et al., 2003; DEL POZO INSFRAN et al., 2007).

A APH é capaz de desnaturar ou modificar proteínas, ativar ou não enzimas e alterar as interações substrato-enzima (BUTZ; TAUSCHER, 2002). Pequenas mudanças no sítio ativo podem levar à perda de atividade de certas enzimas. Como a desnaturação protéica é associada a mudanças conformacionais, ela pode afetar a funcionalidade bioquímica de determinada enzima, como por exemplo, através do aumento ou perda da atividade biológica e das mudanças na especificidade do substrato (HENDRICKX et al., 1998).

As peroxidases ( $\mathrm{POD}$ ) e polifenoloxidases ( $\mathrm{PFO}$ ), presentes na maioria dos vegetais, são as principais responsáveis por alterações indesejáveis das características originais, principalmente as de cor. Essas enzimas catalisam a oxidação de substâncias polifenólicas, naturalmente presentes em vegetais in natura, originando produtos responsáveis pela mudança de cor, características sensoriais e nutricionais (VAMOS-VIGYÁZÓ, 1981). $\mathrm{A} \mathrm{APH}$ pode ser aplicada visando à inativação dessas enzimas, para que o escurecimento enzimático e as mudanças na aparência e nas propriedades sensoriais não ocorram (HENDRICKX et al., 1998).

O objetivo desse trabalho foi avaliar o efeito do processamento de APH sobre as PFO e POD de polpas de açaí, considerando as variáveis de pressão, temperatura e tempo.

\section{Material e métodos}

Polpas de açaí contendo concentração de Sólidos Totais (ST) maior que $14 \%$, obtidas a partir de frutos de açaizeiros com auxílio de despolpadeira em aço inoxidável, foram embaladas em sacos de polietileno e imediatamente resfriadas e congeladas. Depois de acondicionadas em caixas térmicas de Isopor ${ }^{\circ}$, foram transportadas de Belém (PA) para o Rio de Janeiro (RJ), por via aérea. Ao chegar ao laboratório da Embrapa Agroindústria de Alimentos, a polpa de açaí foi descongelada e assepticamente reembalada em sacos constituídos de 5 camadas intercaladas de polietilieno e nylon ${ }^{\star}$, com alta barreira ao oxigênio atmosférico. Cada saco acondicionou cerca de $20 \mathrm{~g}$ de polpa. As bolhas de ar foram removidas e cada saco foi fechado com auxílio de seladora com sistema termo-soldável.

Os tratamentos de APH foram realizados em um equipamento piloto Stansted Fluid Power Ltd., Stansted, Reino Unido, que opera com níveis de pressão de até 900 Mega Pasquali $(\mathrm{MPa})$, com duração de até 30 minutos e temperaturas entre 20 e $90{ }^{\circ} \mathrm{C}$. Como meio pressurizante, foi usada solução de álcool etílico a 70\%. Nesse estudo, foi adotado planejamento fatorial com 2 níveis e com pontos centrais para delineamento experimental de 11 ensaios e o tratamento de dados. Pressão (MPa), temperatura $\left({ }^{\circ} \mathrm{C}\right)$ e tempo (minutos) foram considerados as variáveis de processo (Tabela 1), enquanto que as variáveis de resposta foram o percentual de atividade da peroxidase e de atividade da polifenoloxidase. A matriz do planejamento fatorial com pontos centrais é mostrada na Tabela 2.

Amostras controle (sem tratamento) foram analisadas juntamente com as tratadas. Logo após a pressurização, as variáveis de resposta foram avaliadas, não ultrapassando 30 minutos de espera.

A determinação de atividade das enzimas peroxidase e polifenoloxidase foi realizada de acordo com o método de Cano, Hernández e Ancos (1997), modificado por Domingues (2003). O extrato enzimático para a determinação da atividade enzimática foi obtido através da homogeneização de aproximadamente $15 \mathrm{~g}$ de polpa de açaí, com 30-35 mL de tampão

Tabela 1. Variáveis de processo.

\begin{tabular}{lrcr}
\hline Variáveis de processo & \multicolumn{3}{c}{ Níveis } \\
\cline { 2 - 4 } & \multicolumn{1}{c}{0} & \multicolumn{1}{c}{} \\
\hline Pressão $(\mathrm{MPa})$ & 300 & 400 & 500 \\
Temperatura $\left({ }^{\circ} \mathrm{C}\right)$ & 25 & 30 & 35 \\
Tempo (minutos) & 5 & 10 & 15 \\
\hline
\end{tabular}

Tabela 2. Delineamento experimental de 11 ensaios.

\begin{tabular}{cccc}
\hline Processamento & Pressão $(\mathrm{MPa})$ & Temperatura $\left({ }^{\circ} \mathrm{C}\right)$ & Tempo (minutos) \\
\hline 8 & 300 & 35 & 5 \\
4 & 500 & 25 & 15 \\
5 & 400 & 30 & 10 \\
9 & 300 & 35 & 15 \\
2 & 300 & 25 & 15 \\
10 & 500 & 35 & 5 \\
6 & 400 & 30 & 10 \\
7 & 400 & 30 & 10 \\
1 & 300 & 25 & 5 \\
11 & 500 & 35 & 15 \\
3 & 500 & 25 & 5 \\
\hline
\end{tabular}


fosfato de potássio $0,2 \mathrm{M}, \mathrm{pH} 6,5$, contendo polivinilpirrolidona (PVPP) 1\%, completando-se o volume com água destilada até $50 \mathrm{~mL}$. Após homogeneização por 3 minutos, com intervalos de 30 segundos, o material foi filtrado em papel qualitativo de filtração média, obtendo-se o extrato enzimático.

Para a atividade de peroxidase foram utilizados $0,025 \mathrm{~mL}$ do extrato enzimático e uma mistura reacional composta de $2,7 \mathrm{~mL}$ de tampão fosfato de potássio $0,05 \mathrm{M}, \mathrm{pH}$ 6,5, com $0,2 \mathrm{~mL}$ de p-fenilenodiamina $1 \%(\mathrm{p} / \mathrm{v})$ como doador de hidrogênio e $0,1 \mathrm{~mL}$ de peróxido de hidrogênio $1,5 \%(\mathrm{p} / \mathrm{v})$ como fonte de oxigênio (DOMINGUES, 2003).

Para a atividade da polifenoloxidase foram utilizados $0,2 \mathrm{~mL}$ do extrato enzimático e uma mistura composta de $3,0 \mathrm{~mL}$ de catecol 0,07 M em tampão fosfato de sódio 0,05 M e pH 6,5.

As atividades das enzimas peroxidase e polifenoloxidase foram determinadas em espectrofotômetro SPECORD $205 \mathrm{UV} /$ Visível com leituras nos comprimentos de onda de 485 e $420 \mathrm{~nm}$, a $25^{\circ} \mathrm{C}$, por 5 minutos, respectivamente. Essas determinações foram realizadas em triplicata e calculadas através da variação da absorbância versus tempo. A avaliação do efeito do processamento sobre as atividades das enzimas foi definida como a relação entre a atividade inicial antes do tratamento, considerada controle (100\%), e após o tratamento (atividade final), calculada pela Equação 1.

$\%$ de atividade enzimática $=\frac{\text { atividade enzimática final } \times 100}{\text { atividade enzimática inicial }}$

\section{Resultados e discussão}

$\mathrm{Na}$ Tabela 3 são apresentados os resultados da análise de variância do modelo quadrático para os 11 ensaios. A curvatura foi um fator significativo $(\mathrm{p}<0,05)$, confirmando que o modelo quadrático é adequado ao expressar o comportamento da POD, submetida às variáveis do experimento. Dentre as três variáveis, pressão, temperatura e tempo, somente o tempo apresentou significância $(\mathrm{p}<0,05)$ (Tabela 3$)$. Já no trabalho de Hendrickx et al. (1998), sobre a atividade enzimática da POD em feijões verdes, não houve efeito significativo com aumento de tempo.

O efeito do processo da APH na atividade da POD da polpa de açaí, considerando as interações entre as variáveis não foi significativo, mostrando, nesse caso, que a temperatura só foi importante quando interagiu com uma das duas outras variáveis (Tabela 3). O mesmo foi observado por Hendrickx et al. (1998) ao submeterem feijões verdes a APH a $600 \mathrm{MPa}$, quando combinada à temperatura.

Polpas de açaí submetidas a processamentos com 15 minutos de exposição a 300 e $500 \mathrm{MPa}$ apresentaram, independentemente do nível de pressão e temperatura, percentual de POD inferior às processadas por 5 minutos a 300 e $500 \mathrm{MPa}$, mostrando a importância do tempo de trabalho na atividade da POD (Figura 1). Os percentuais de atividade da POD dos tratamentos a 15 minutos foram menores quando comparadas com as controle (100\%), com exceção do tratamento a $300 \mathrm{MPa} / 35^{\circ} \mathrm{C} / 15$ minutos, em que foi obtido $102,78 \pm 6,31 \%$ de atividade da POD (Figura 1).

Na Figura 1, quando a polpa de açaí foi submetida a $300 \mathrm{MPa}$ por 5 minutos e por 15 minutos, comportamentos opostos na atividade da POD foram observados, em relação ao tempo e à temperatura. Após ser tratada por 5 minutos, houve redução do percentual de atividade com o aumento da temperatura para $35^{\circ} \mathrm{C}$ (Figura 1), entretanto, não foram observadas diferenças estatisticamente significativas $(\mathrm{p}<0,05)$. Quando as

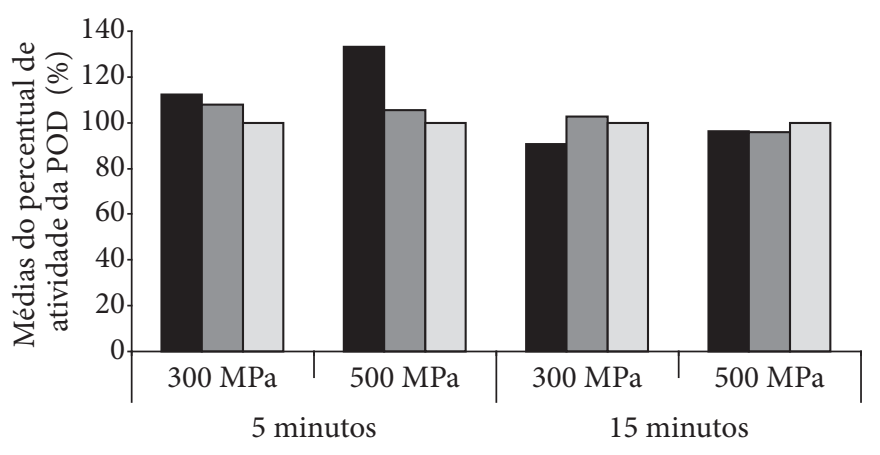

$25^{\circ} \mathrm{C} \quad \square 35^{\circ} \mathrm{C} \quad \square$ Controle (polpa não pressurizada)

Figura 1. Médias dos percentuais de atividade da POD em polpas de açaí pressurizadas a 300 e $500 \mathrm{MPa}$, a 25 e $35^{\circ} \mathrm{C}$, por 5 e 15 minutos.

Tabela 3. Análise de variância do modelo quadrático para o percentual de atividade da POD em polpas de açaí pressurizadas a 300,400 e $500 \mathrm{MPa}$, a 25,30 e $35^{\circ} \mathrm{C}$, por 5,10 e 15 minutos $\left(R^{2}=0,77\right)$.

\begin{tabular}{|c|c|c|c|c|c|}
\hline Fator & Soma quadrática & Grau de liberdade & Média quadrática & $\mathrm{F}$ & $\mathrm{p}$ \\
\hline Curvatura & 295,99 & 1 & 295,99 & 5,9076 & $0,0229^{*}$ \\
\hline Pressão (MPa) (1) & 119,18 & 1 & 119,18 & 2,3786 & 0,1361 \\
\hline Temperatura $\left({ }^{\circ} \mathrm{C}\right)(2)$ & 170,42 & 1 & 170,42 & 3,4014 & 0,0775 \\
\hline Tempo (minutos) (3) & 2034,60 & 1 & 2043,60 & 40,7877 & $0,0000^{*}$ \\
\hline Interação (1) e (2) & 492,95 & 1 & 492,95 & 9,8386 & $0,0045^{*}$ \\
\hline Interação (1) e (3) & 159,31 & 1 & 159,31 & 3,1797 & 0,0872 \\
\hline Interação (2) e (3) & 760,37 & 1 & 760,37 & 15,1761 & $0,0007^{*}$ \\
\hline Interação (1), (2) e (3) & 52,39 & 1 & 52,39 & 1,0456 & 0,3167 \\
\hline Erro & 1202,48 & 24 & 50,10 & - & - \\
\hline Soma quadrática total & 5296,69 & 32 & - & - & - \\
\hline
\end{tabular}

*Nível p significativo em nível de confiança de $95 \%(\mathrm{p}<0,05)$. 
amostras foram tratadas por 15 minutos, nas mesmas condições de pressurização, o aumento da temperatura resultou na ativação da POD (Figura 1).

Quando foram aplicadas pressões de $300 \mathrm{MPa}$ a $25^{\circ} \mathrm{C}$, por 15 minutos, na polpa de açaí, o percentual de atividade da POD se reduziu a $90,74 \pm 11,26 \%$. O mesmo efeito foi observado por Hernández e Cano (1998), apesar da ampla faixa de pressão utilizada, em purês de tomate, considerando entre 50 e $400 \mathrm{MPa}$, à temperatura ambiente $\left(20^{\circ} \mathrm{C}\right)$ e combinadas a temperaturas de 30 a $60^{\circ} \mathrm{C}$, durante 15 minutos de exposição.

Nas polpas de açaí pressurizadas a $500 \mathrm{MPa}$ por 15 minutos foram registrados percentuais de atividade da POD de $96,15 \pm 1,92 \%$ a $25^{\circ} \mathrm{C}$ e de $95,97 \pm 7,07 \%$ a $35^{\circ} \mathrm{C}$ (Figura 1 ). Entretanto, quando Hernández e Cano (1998) adotaram pressurização de 400-500 MPa, combinada às temperaturas de $30 \mathrm{a}$ $60^{\circ} \mathrm{C}$, observaram aumento de atividade da POD em purês de tomate. Esse comportamento em polpas de açaí foi observado somente quando as amostras foram submetidas a $500 \mathrm{MPa}$ a $25^{\circ} \mathrm{C}$ por 5 minutos de exposição, quando ocorreu ativação da POD de $32,98 \%$ em comparação a polpas controle que correspondiam a $100 \%$ de atividade (Figura 1 ).

Segundo Cano, Hernández e Ancos (1997), a inativação depende das características do produto, do tipo da enzima e das condições de processo. Hernandéz e Cano(1998), em purês de tomate, e Cano, Hernández e Ancos (1997), em purês de morangos, obtiveram as melhores inativações de POD quando esses produtos foram pressurizados a $350 \mathrm{MPa}$, à temperatura ambiente $\left(20^{\circ} \mathrm{C}\right)$ e a $230 \mathrm{MPa}$, a $43^{\circ} \mathrm{C}$, por 15 minutos, respectivamente.

Na Tabela 4 é apresentada a análise de variância do modelo adotado para o percentual de atividade da PFO. A curvatura possui importância significativa $(\mathrm{p}<0,05)$, indicando que esse modelo pode ser próprio à análise dos percentuais de atividade dessa enzima na polpa de açaí sob efeito dos processamentos de APH. A pressão e a temperatura, isoladamente, também foram fatores significativos em nível de confiança de 95\% ( $\mathrm{p}<0,05)$, bem como a interação entre eles (Tabela 4).

Processamentos hidrostáticos em polpas de açaí a $300 \mathrm{MPa}$, 5 minutos e 15 minutos, resultaram em percentuais de atividade de PFO médios menores que amostras tratadas a $500 \mathrm{MPa}$ por 5 minutos e 15 minutos, exceto quando pressurizadas a
$500 \mathrm{MPa}$, a $35^{\circ} \mathrm{C}$ durante 15 minutos $(70,25 \pm 6,12 \%)$. Nesse último caso, o valor obtido foi inferior às atividades da $\mathrm{PFO}$ nas polpas de açaí tratadas a $300 \mathrm{MPa}$, a $35^{\circ} \mathrm{C}$, por 15 minutos $(75,74 \pm 4,89 \%)$ (Figura 2).

Tratamentos de polpa de açaí sob $300 \mathrm{MPa}$, tanto a $25^{\circ} \mathrm{C}$, quanto a $35^{\circ} \mathrm{C}$ foram suficientes para promover a inativação parcial da $\mathrm{PFO}$, reduzindo seus percentuais em relação às amostras controle (100\%) para $65,79 \pm 7,66 \%$ e 53,25 $\pm 1,78 \%$, respectivamente, quando o tempo de processo foi de 5 minutos (Figura 2). Castellari et al. (1997), quando submeteram mostos de uvas brancas à pressão hidrostática de $600 \mathrm{MPa}$, a $15^{\circ} \mathrm{C}$, por 10 minutos, obtiveram valores médios de $61,6 \%$ para as atividades de PFO. Yen e Lin (1996) também verificaram que havia $63 \%$ de atividade de PFO em purê de goiaba submetido a $600 \mathrm{MPa}$, a $25^{\circ} \mathrm{C}$, por 5 minutos. Quando a polpa de açaí foi tratada por 15 minutos, a $300 \mathrm{MPa}$, a $25^{\circ} \mathrm{C}$, a atividade da PFO foi de $83 \pm 3,44 \%$ (Figura 2). Semelhante resultado ( $86 \%$ ) foi encontrado por Yen e Lin (1996), quando submeteram purês de goiaba a $400 \mathrm{MPa}$, a $25^{\circ} \mathrm{C}$, por 15 minutos. No entanto, Asaka e Hayashi(1991) ao tratarem pêras fatiadas nas mesmas condições

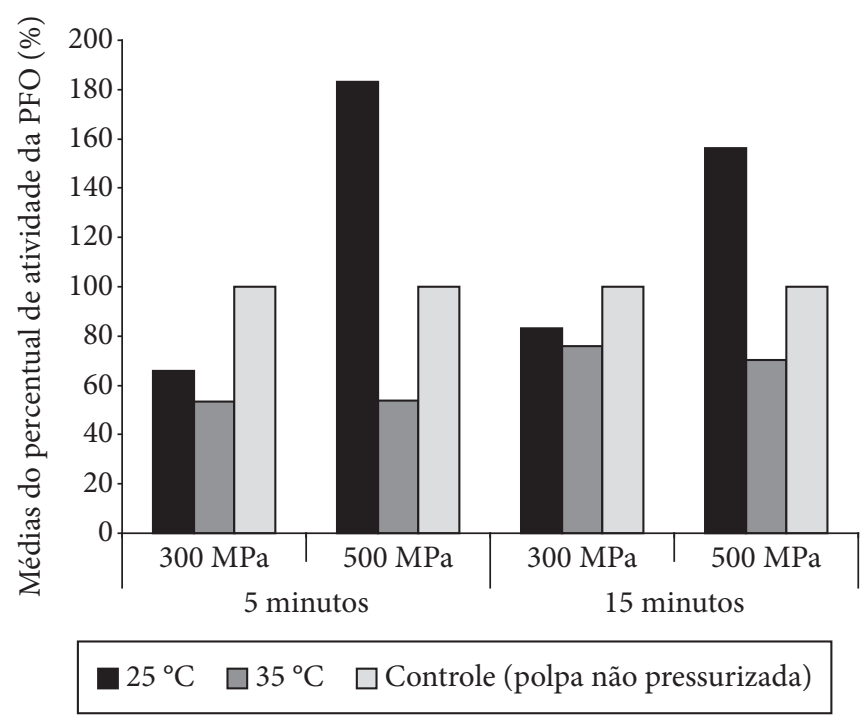

Figura 2. Médias dos percentuais de atividade da PFO em polpas de açaí pressurizadas a 300 e $500 \mathrm{MPa}$, a 25 e $35^{\circ} \mathrm{C}$, por 5 e 15 minutos.

Tabela 4. Análise de variância do modelo quadrático para percentual de atividade da PFO em polpas de açaí pressurizadas a 300 , 400 e $500 \mathrm{MPa}$, a 25,30 e $35^{\circ} \mathrm{C}$, de 5 a 15 minutos $\left(\mathrm{R}^{2}=0,88\right)$.

\begin{tabular}{|c|c|c|c|c|c|}
\hline Fator & Soma quadrática & Grau de liberdade & Média quadrática & $\mathrm{F}$ & $\mathrm{p}$ \\
\hline Curvatura & 3656,76 & 1 & 3656,76 & 12,0418 & $0,0020^{*}$ \\
\hline Pressão (MPa) (1) & 12928,04 & 1 & 12928,04 & 42,5723 & $0,0000^{*}$ \\
\hline Temperatura $\left({ }^{\circ} \mathrm{C}\right)(2)$ & 20731,70 & 1 & 20731,70 & 68,2699 & $0,0000^{*}$ \\
\hline Tempo (minutos) (3) & 330,06 & 1 & 30,06 & 1,0869 & 0,3075 \\
\hline Interação (1) e (2) & 14366,10 & 1 & 14366,10 & 47,3079 & $0,0000^{*}$ \\
\hline Interação (1) e (3) & 935,37 & 1 & 935,37 & 3,0802 & 0,0920 \\
\hline Interação (2) e (3) & 877,02 & 1 & 877,02 & 2,8881 & 0,1022 \\
\hline Interação (1), (2) e (3) & 542,37 & 1 & 542,37 & 1,7861 & 0,1939 \\
\hline Erro & 7288,14 & 24 & 303,67 & - & - \\
\hline Soma quadrática total & 61655,57 & 32 & - & - & - \\
\hline
\end{tabular}

${ }^{*}$ Nível p significativo em nível de confiança de $95 \%(\mathrm{p}<0,05)$. 
dos purês de goiaba (YEN; LIN, 1996) obtiveram aumento da atividade da PFO. Isso prova que os comportamentos de polifenoloxidases são diversificados, dependendo da matriz e das condições dos processos (CASTELLARI et al., 1997).

Resultados semelhantes ao da polpa de açaí, em que o tratamento a $300 \mathrm{MPa}$ reduziu a atividade da PFO, também foram encontrados por Cano, Hernández e Ancos (1997) em purês de morango, onde até $285 \mathrm{MPa}$, à temperatura ambiente $\left(20^{\circ} \mathrm{C}\right)$, por 15 minutos de processamento, a atividade da $\mathrm{PFO}$ teve decréscimo. Contudo, em tratamentos com níveis de pressão mais elevados, entre 285 e $400 \mathrm{MPa}$, a inativação da PFO se reduzia; embora a $285 \mathrm{MPa}$ os autores observassem ainda $40 \%$ de atividade residual de PFO. Esses autores, ao combinarem temperaturas de 20 e $60^{\circ} \mathrm{C}$ com pressão observaram significativo aumento de atividade de PFO. Quando trataram a $400 \mathrm{MPa}$, a $60^{\circ} \mathrm{C}$, por 15 minutos, os resultados em atividades de $\mathrm{PFO}$ foram iguais às amostras controle (BUTZ; TAUSCHER, 2002).

Efeitos contrários aos obtidos em polpa de açaí e em purê de morango (CANO; HERNÁNDEZ; ANCOS, 1997) foram observados por Hernández e Cano (1998) em purês de tomate, em que pressões menores que $200 \mathrm{MPa}$ aumentavam a atividade da PFO. No entanto, entre 200 e $500 \mathrm{MPa}, \mathrm{a} 20^{\circ} \mathrm{C}$, por $15 \mathrm{minu}$ tos de processo, perdas significativas da atividade de PFO eram observadas, ao passo que a submissão a pressões de $500 \mathrm{MPa}$ combinadas a diferentes temperaturas $\left(30-60{ }^{\circ} \mathrm{C}\right)$ promoviam a completa desnaturação dessa enzima.

As enzimas POD e PFO da polpa de açaí desempenharam diferentes reações diante das condições a que foram expostas, diferindo quanto à importância de fatores nos processos e quanto às condições ótimas de inativação entre níveis de pressão, temperatura e tempo. A atividade da POD nas polpas de açaí pressurizadas se mostrou bastante estável, pois após o tratamento mais eficiente, ou seja, aquele que mais inativou a POD, esta enzima apresentou atividade residual de $90,74 \pm 11,26 \%$, confirmando sua baro-resistência. A estabilidade da POD pode ser explicada devido ao efeito diferenciado da APH sobre isoperoxidases, da mesma forma que o tratamento térmico exerce, pois em extratos vegetais a atividade da POD tem sido exaustivamente estudada e os resultados têm mostrado que a termo-sensibilidade é diferente (SANTOS, 2001; CLEMENTE, 2002; DOMINGUES, 2003).

Em tratamentos a $500 \mathrm{MPa}$, a $25^{\circ} \mathrm{C}$, por 5 minutos, a atividade da POD registrada foi a maior, com 132,98 \pm 4,84\% de ativação. Esse fenômeno também aconteceu com a PFO da polpa de açaí, pois nesse mesmo processamento a atividade da PFO determinada foi de $183,03 \pm 4,58 \%$. Diversamente da $\mathrm{POD}$, a PFO conseguiu ser bastante inativada dentre os vários processos, em geral naqueles a $35^{\circ} \mathrm{C}$, que tiveram percentuais de até $53,25 \pm 1,78 \%$.

O máximo de informações é necessário para avaliar a relação entre a baroestabilidade de enzimas e o universo de fatores que contribuem ou protegem o efeito do processamento de APH sobre a POD e a PFO de vegetais (VAMOS-VIGYÁZÓ, 1981). A inativação enzimática pela APH depende das características do meio, como já relatado por diversos autores (OGAWA et al., 1990; ROVERE, 1995; CASTELLARI et al., 1997), bem como da temperatura e do tempo de tratamento (VÁMOS-VIGYÁZÓ, 1981).

\section{Conclusões}

O processamento de alta pressão hidrostática desempenhou efeitos diferentes sobre a atividade das enzimas peroxidase (POD) e polifenoloxidase (PFO) da polpa de açaí. A POD teve sua atividade levemente reduzida em alguns tratamentos a 15 minutos, mas de uma maneira geral a sua atividade foi aumentada, chegando a uma ativação máxima de $32,98 \%$, quando tratada a $500 \mathrm{MPa}$, a $25^{\circ} \mathrm{C}$, por 5 minutos. A PFO também teve sua atividade estimulada quando as polpas foram submetidas a $500 \mathrm{MPa}, 25^{\circ} \mathrm{C}$, por 5 ou 15 minutos, mas, em geral, processos a $35^{\circ} \mathrm{C}$, juntamente com a pressão, reduziram sua atividade em até 53,25\%. Assim, não foi possível chegar a uma condição ótima única onde se pudesse obter a máxima inativação de ambas as enzimas da polpa de açaí.

\section{Agradecimentos}

Agradecemos à CAPES pela bolsa concedida à autora Ellen Mayra da Silva Menezes, mestranda do Curso de Pós-Graduação em Ciência e Tecnologia de Alimentos da UFRRJ.

\section{Referências bibliográficas}

ALEXANDRE, D.; CUNHA, R. L.; HUBINGER, M. D. Conservação do açaí pela tecnologia de obstáculos. Ciência e Tecnologia de Alimentos, v. 24, n. 1, p. 114-119, 2004.

ASAKA, M.; HAYASHI, R. Activation of Polyphenoloxidase in Pear Fruits by High Pressure Treatment. Agricultural and Biological Chemistry, v. 55, n. 9, p. 2439-2440, 1991.

BEZERRA, J. A. No Ceará tem disso, sim. Agricultores nordestinos adotam parcerias para multiplicar a produção e investem em tecnologia para aumentar as exportações de frutas frescas, ajudando o Brasil a conquistar novos mercados. Globo Rural Agropecuária e Negócios, n. 230, p. 44-52, dez. 2004.

BUTZ, P. et al. Changes in functional properties of vegetables induced by high pressure treatment. Food Research International, v. 35, n. 2, p. 295-300, 2002a.

BUTZ, P.; FERNÁNDEZ GARCÍA, A.; TAUSCHER, B. Influence of high pressure treatment on sensorial and nutritional quality of fruit and vegetables. In: HAYASHI, R. Trends in High Pressure Bioscience and Biotechnology. [S.I.]: Elsevier Science, 2002b, p. 417-421.

BUTZ, P. et al. Influence of ultra high pressure processing on fruit and vegetable products. Journal of Food Engineering, v. 56, n. 2-3, p. 233-236, 2003.

BUTZ, P.; TAUSCHER, B. Emerging Technologies: chemical aspects. Food Research International, v. 35, n. 2, p. 279-284, 2002.

CANO, M. P.; HERNÁNDEZ, A.; ANCOS, B. High Pressure and Temperature Effects on Enzyme Inactivation in Strawberry and Orange Products. Journal of Food Science, v. 62, n. 1, p. 85-88, 1997.

CASTELLARI, M. et al. Effects of high pressure processing on polyphenoloxidase enzyme activity of grape musts. Food Chemistry, v. 60, n. 4, p. 647-649, 1997.

CLEMENTE, E. Peroxidase from oranges (Citrus sinenses (L.) Obsbeck). European Food Research Technology, n. 215, p. 164-168, 2002. 
DEL POZO INSFRAN, D. et al. Stability of Copigmented Anthocyanins and Ascorbic Acid in Muscadine Grape Juice Processed by High Hydrostatic Pressure. Journal of Food Science, v. 72, n. 4, p. 247-253, 2007.

DOMINGUES, A. M. Avaliação do Processo de pasteurização térmica de néctar de abacaxi (Ananás comosus L.). Seropédica, 2003. 91 p. Dissertação - (Mestrado em Ciência e Tecnologia de Alimentos), Universidade Federal Rural do Rio de Janeiro.

GARCIA-PALAZON, A. et al. The effects of high hydrostatic pressure on $\beta$-glucosidase, peroxidase and polyphenoloxidase in red raspberry (Rubus idaeus) and strawberry (Fragaria $x$ ananassa). Food Chemistry, v. 88, n. 1, p. 7-10, nov. 2004.

HENDRICKX, M. et al. Effects of high pressure on enzymes related to food quality. Trends in Food Science \& Technology, v. 9, n. 5, p. 197-203, 1998.

HERNÁNDEZ, A.; CANO, M. P. High-Pressure and Temperature Effects on Enzyme Inactivation in Tomato Puree. Journal of Agricultural and Food Chemistry, v. 46, n. 1, p. 266-270, 1998.

MAPA - Ministério da Agricultura, Pecuária e Abastecimento. Agronegócio Brasileiro: Uma oportunidade de investimentos. Disponível em: <http:www.agricultura.gov.br>. Acesso em: 25 nov. 2004.

MENEZES, E. M. S. Efeito da alta pressão hidrostática em polpa de aecia pré-congelada (Euterpe oleracea, Mart.). Rio de Janeiro, 2005. 83 p. Dissertação - (Mestrado em Ciência e Tecnologia de alimentos), Universidade Federal Rural do Rio de Janeiro.

MONTEIRO, S. Açaí. De fruta exótica a vedete de consumo. Frutas \& derivados, v. 1, n. 2, p. 29-32, 2006.

OGAWA, H. et al. Pressure Inactivation of Yeasts, Molds, and Pectinesterase in Satsuma Mandarin Juice: Effects of Juice Concentration, $\mathrm{pH}$, and Organic Acids, and Comparison with Heat Sanitation. Agricultural and Biological Chemistry, v. 54, n. 5, p. 1219-1225, 1990.
OLIVEIRA, M. S. P. et al. Cultivo do Açaizeiro para Produção de Frutos. Belém, Pará: Embrapa Amazônia Oriental, 2002. (Circular Técnica, n. 26).

ROGEZ, H. Açaí: preparo, composição e melhoramento da conservação. 1 ed. Belém, PA: Ed. Universidade Federal do Pará EDUFA, 2000. $313 \mathrm{p}$.

ROVERE, P. The third dimension of food technology. Tecnologie Alimentari Sistemi per produrre, n. 4, p. 2-8, 1995.

SABAA-SRUR, A.; TORRES, A. T.; MENEZES, E. M. S. Contribuição ao conteúdo nutricional de polpa de açaí (Euterpe oleracea Mart) liofilizada. In: XIX Congresso Brasileiro de Ciência e Tecnologia de Alimentos, 19, 2004, Pernambuco. Programa Final... Recife: Sociedade Brasileira de Ciência e Tecnologia de Alimentos, 2004. $156 \mathrm{p}$.

SAN-MARTÍN, M. F.; BARBOSA-CÁNOVAS, G. V.; SWANSON, B. G. Food Processing by High Hydrostatic Pressure. Critical Reviews in Food Science and Nutrition, v. 42, n. 6, p. 627-645, 2002.

SANTOS, E. R. Caracterização Bioquímica da Peroxidase e Polifenoloxidase de Açaí (Euterpe oleracea). Campinas, 2001. 104 p. Dissertação - (Mestrado em Ciência de Alimentos), Faculdade de Engenharia de alimentos - UNICAMP.

SOUSA, M. A. C. et al. Suco de açaí (Euterpe oleracea, Mart.): avaliação microbiológica, tratamento térmico e vida de prateleira. Acta Amazônica, v. 36, n. 4, p. 483-496, 2006.

VÁMOS-VIGYÁZÓ, L. Polyphenoloxidase and peroxidase in fruits and vegetables. Critical Reviews in Food Science and Nutrition, v. 15, p. 49-127, 1981.

YEN, G.; LIN, H. Comparison of high pressure treatment and thermal pasteurization effects on the quality and shelf life of guava puree. International Journal of Food Science and Technology, v. 31, n. 2, p. 205-213, 1996.

YUYAMA, L. K. O. et al. Açaí (Euterpe oleracea, Mart.): Qual o seu potencial Nutricional? In: Congresso Brasileiro de Fruticultura, 17, 2004, Florianópolis. Anais.... Santa Catarina: Sociedade Brasileira de Fruticultura, 2004. 